
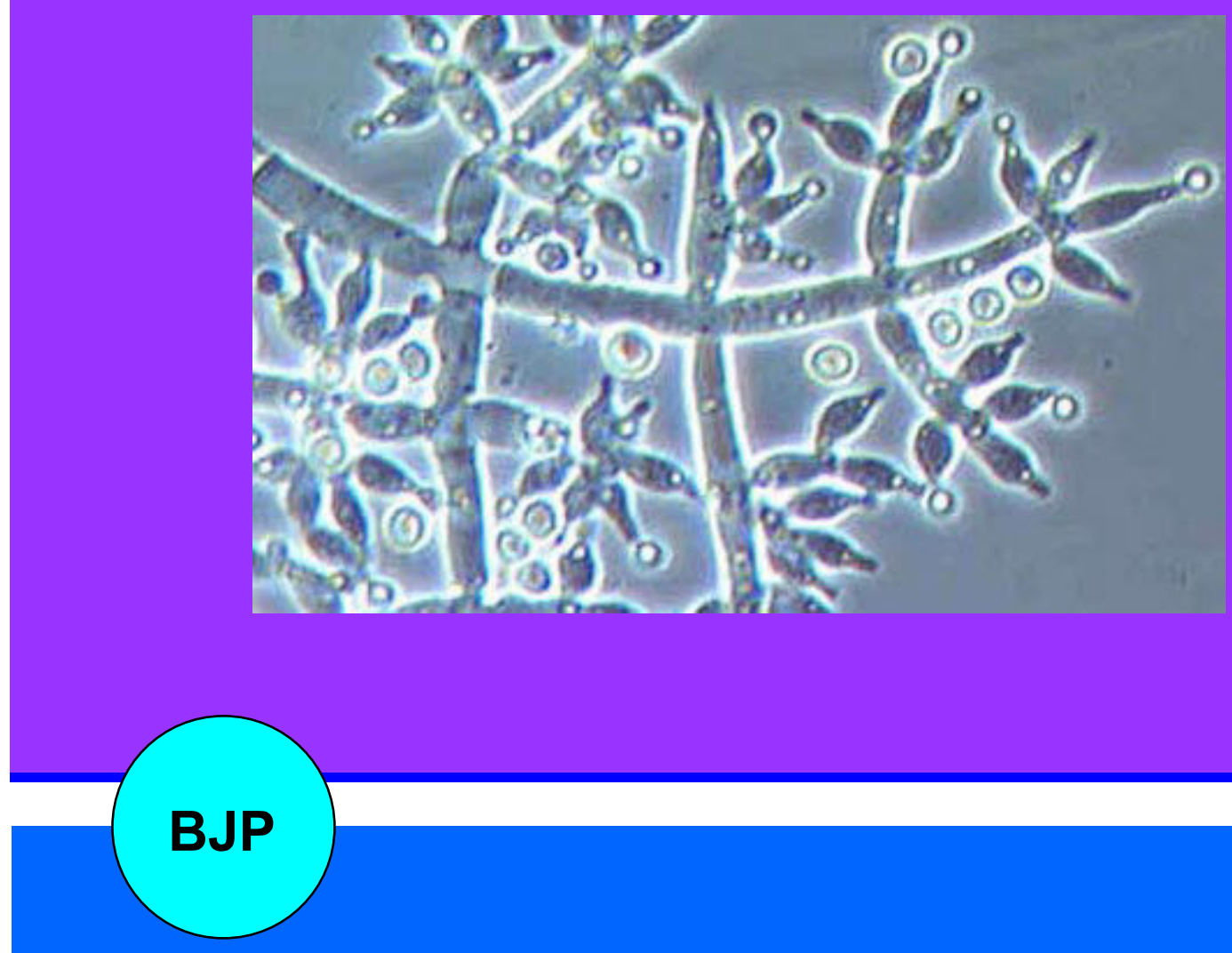

Bangladesh Journal of Pharmacology

Research Article

Trichoderma harzianum: A new fungal source for the production of cyclosporin A 
Abstracted/indexed in Academic Search Complete, Asia Journals Online, Bangladesh Journals Online, Biological Abstracts, BIOSIS Previews, CAB Abstracts, Current Abstracts, Directory of Open Access Journals, EMBASE/Excerpta Medica, Google Scholar, HINARI (WHO), International Pharmaceutical Abstracts, Open J-gate, Science Citation Index Expanded, SCOPUS and Social Sciences Citation Index;

ISSN: $1991-0088$

\title{
Trichoderma harzianum: A new fungal source for the production of cyclosporin A
}

\author{
Asma Azam, Tehmina Anjum and Wajiha Irum
}

Institute of Plant Pathology, University of the Punjab, Quaid-e-Azam Campus, Lahore, Pakistan.

\begin{tabular}{|c|c|}
\hline \multicolumn{2}{|l|}{ Article Info } \\
\hline Received: & \\
\hline & \\
\hline Available Online: & \\
\hline \multicolumn{2}{|c|}{ DOI: 10.3329/bjp.v7i1.10084 } \\
\hline \multicolumn{2}{|c|}{$\begin{array}{l}\text { Cite this article: } \\
\text { Azam A, Anjum T, Irum W. Trichoder } \\
\text { ma harzianum: A new fungal source } \\
\text { for the production of cyclosporin A } \\
\text { Bangladesh J Pharmacol. 2012; } 7: 33 \\
35 \text {. }\end{array}$} \\
\hline
\end{tabular}

\begin{abstract}
Pure cultures of Trichoderma harzianum, T. aureoviride, T. reesei, T. koningii and T. hemantum were checked for their potential to produce cyclosporin A. Production medium used for drug production was consisted of: glucose, $5 \%$; peptone, $1 \%$; $\mathrm{KH}_{2} \mathrm{PO}_{4}, 0.5 \%$; KCL, $0.25 \%$ (w/v). Whereas, butyl acetate was used to extract the fermentation medium for cyclosporine A. This was then analyzed through high performance liquid chromatography and the chromatograms obtained were compared with that of cyclosporine and with the external standard cyclosporin A $98.5 \%$ pure. Only chromatogram of $T$. harzianum showed a peak at 2.78 , which was comparable with both the standards. Mass spectroscopy of this peak showed [CsA $+\mathrm{H}]+$ ion of $m / z 1203$. The amount of drug calculated was $44.06 \mu \mathrm{g} / \mathrm{mL}$.
\end{abstract}

\section{Introduction}

Cyclosporin A is a member of the group of cyclic undecapeptides with anti-inflammatory, mmunosuppressive, antifungal and antiparasitic properties (Sallam et al., 2005). It is used extensively in the prevention and treatment of graft-versus-host reactions in bone marrow transplantation and for the prevention of rejection of kidney, heart and liver transplants. Cyclosporin A is a major secondary metabolite usually produced by an aerobic filamentous fungus, Tolypocladium niveum (Park et al., 2006). Although cyclosporin A was initially developed as an antifungal antibiotic (Deo et al., 1984), it is currently prescribed as one of the most important immunosuppressive drugs for the treatment of organ transplants, as well as patients with autoimmune diseases, including AIDS, owing to its superior T-cell specificity and low levels of myelotoxicity (Borel, 1986). It consists of 11 amino acids with a molecular weight of 1202.6 and occurs as a white solid with a melting point of 148 to $151^{\circ} \mathrm{C}$ (natural) and 149 to $150^{\circ} \mathrm{C}$ (synthetic). It is stable in solution at temperatures below $30^{\circ} \mathrm{C}$ but is sensitive to light, cold, and oxidiza- tion (IARC, 1990).

The drug was first isolated from T. inflatum (Gams, 1971) and after that very few studies were planned to explore other sources for its production. Until now most of the research work related to cyclosporin A deals with $T$. inflatum and Aspergillus terreus. The present study was designed to explore Trichoderma species for this drug production.

\section{Materials and Methods}

\section{Acquisition and maintenance of T. harzianum}

Pure cultures T. harzianum (FCBP 140), T. aureoviride (FCBP 234), T. reesei (FCBP 271), T. koningii (FCBP 585) and T. hemantum (FCBP 907) were obtained from the First Fungal Culture Bank of Pakistan (FCBP) and maintained on Malt extract agar (MEA) medium and preserved at $4^{\circ} \mathrm{C}$.

\section{Seed inoculum preparation}

Malt Yeast extract (MY) medium was selected as seed 
medium for inoculum preparation of selected fungi. MY medium is composed of malt extract $2 \%$, yeast extract $0.4 \%$ and initial $\mathrm{pH}$ was adjusted to 5.7 using 1.0 $\mathrm{M} \mathrm{HCl}$. $50 \mathrm{~mL}$ of $\mathrm{MY}$ medium was prepared and poured in Erlenmeyer flasks (250 mL capacity) plugged with cotton plugs. These prepared medium flasks were sterilized by autoclaving at $121^{\circ} \mathrm{C}$ and $15 \mathrm{lb} /$ inch 2 pressure for 15-20 min. By using cork borer, $0.8 \mathrm{~cm}$ disk of five days old cultures on MEA of Trichoderma species were inoculated in sterilized medium in flasks. The inoculated flasks were incubated on orbital shaker at $200 \mathrm{rpm}$ for 72 hours at $30^{\circ} \mathrm{C}$ (Borel et al., 1977). The inoculum of all the strains was prepared by the same procedure.

\section{Cultivation}

For cultivation $50 \mathrm{~mL}$ production medium specially design for cyclosporin A production, was prepared with following composition: Glucose, $5 \%$; peptone, $1 \%$; $\mathrm{KH}_{2} \mathrm{PO}_{4}, 0.5 \%$; KCL, $0.25 \%$ (w/v), at $\mathrm{pH}$ 5.3. According to the methodology of Agathos et al. (1986) $5 \mathrm{~mL}$ of seed inoculum from each isolate was introduced into $250 \mathrm{~mL}$ Erlenmeyer flasks containing $50 \mathrm{~mL}$ of production medium. The fermentation was continued at $28 \pm 1^{\circ} \mathrm{C}$ for 10 days, at $200 \mathrm{rpm}$.

\section{Cyclosporin A extraction}

Harvested fermentation medium was mixed with 30 $\mathrm{mL}$ of butyl acetate and stirred at $200 \mathrm{rpm}$ for 24 hours at $30^{\circ} \mathrm{C}$. Organic layer was formed after 24 hours, which was separated by separating funnel and evaporated under vacuum till dryness. Dried extract was weighed and dissolved in $30 \mathrm{~mL}$ methanol.

\section{Measurement of fungal biomass}

The aqueous layer of cultivation medium containing fungal pellets was filtered for harvest of biomass. The filtration was performed by using Whatman filter paper No. 1. The fresh biomass was collected on the filter paper by using a conical funnel. Filters were slightly rinsed with water 1-2 times for the washing of media and weighed on digital weighing machine. The filters were dried in oven at $40^{\circ} \mathrm{C}$ and re-weighed after cooling. Following formula was used to calculate the dry biomass:

Fungal dry biomass $=$ weight of filter paper - weight of dry filtrate.

\section{Cyclosporin A analysis}

Level of cyclosporin A in the crude extract was analyzed by high performance liquid chromatography (HPLC). HPLC was carried out using Hitachi system consisting of L-2100/2130 pump, L-2420 UV-VIS detector with a detection span from 190 to $900 \mathrm{~nm}$.

Analysis was done using a $\mathrm{C}_{18}$ column with a $5 \mu \mathrm{m}$ particle size, and acetonitrile:methanol:water
(42.5:20:37.5, v/v) as mobile phase at a flow rate of 0.8 $\mathrm{mL} / \mathrm{min}$ with UV detection at $215 \mathrm{~nm}$.

\section{Cyclosporin A confirmation}

For initial confirmation of cyclosporin A, Sandimmun Neoral ${ }^{\circledR}$ capsule (Novartis) containing $100 \mathrm{mg}$ of cyclosporin was used. For this purpose $100 \mu \mathrm{L}$ from capsule was taken with the help of micropippet and dissolved in $10 \mathrm{~mL}$ of methanol. Then, HPLC of this solution was carried out according to the conditions mentioned above.

The retention time and peak area of the samples were compared for final confirmation and quantification, with the external standard cyclosporin A 98.5\% pure (Sigma-Aldrich, Fluka). The standard was analyzed under same conditions as described.

\section{Estimation of cyclosporin A}

The cyclosporin A level in crude extracts was determined by the following formula: \% cyclosporin A by weight $=$

\section{$\underline{\text { As Wr Vs }} \times$ purity of reference ArWsVr}

Where, $\mathbf{A}_{\mathbf{s}}$ is area of sample peak; $\mathbf{A}_{\mathbf{r}}$ is area of reference peak; $\mathbf{W}_{\mathbf{r}}$ is weight of reference material in grams; $\mathbf{W}_{\mathbf{s}}$ is weight of sample in grams; $\mathbf{V}_{\mathbf{s}}$ is volume of sample; $\mathbf{V}_{\mathbf{r}}$ is volume of reference material.

The area of sample peaks and of reference peak was calculated from the chromatograms obtained by HPLC program LaChrom Elite.

\section{Mass spectroscopy}

The ESI/MS spectrum was obtained from singlequadrupole mass spectrometer. Sample was introduced using a silica capillary at a flow rate of $4.0 \mu \mathrm{L} / \mathrm{min}$. The nebulizer gas was optimized and set at a rate of 1.6 $\mathrm{L} / \mathrm{min}$, and an electrospray potential of $4200 \mathrm{~V}$ was applied in the interface sprayer. A curtain gas of ultrapure nitrogen was pumped into the interface at the rate of $1.2 \mathrm{~L} / \mathrm{min}$.

\section{Results and Discussion}

Trichoderma as antagonists controlling wide range of pathogens are well documented (Ajith and Lakshmidevi, 2010). As cyclosporin A is also known for its antifungal properties, five species of Trichoderma were checked for their potential to produce this drug. The drug extracted in butyl acetate was confirmed as cyclosporin A by comparing chromatograms with Sandimmun Neoral ${ }^{\circledR}$ capsules containing cyclosporin A as active ingredient and pure cyclosporin A. Sandimmun Neoral ${ }^{\circledR}$ capsules showed a clear peak at 2.77 whereas peak at 2.8 was recorded by authentic compound (Figure 1, Figure 2). In a previous study, Sallam et al. 


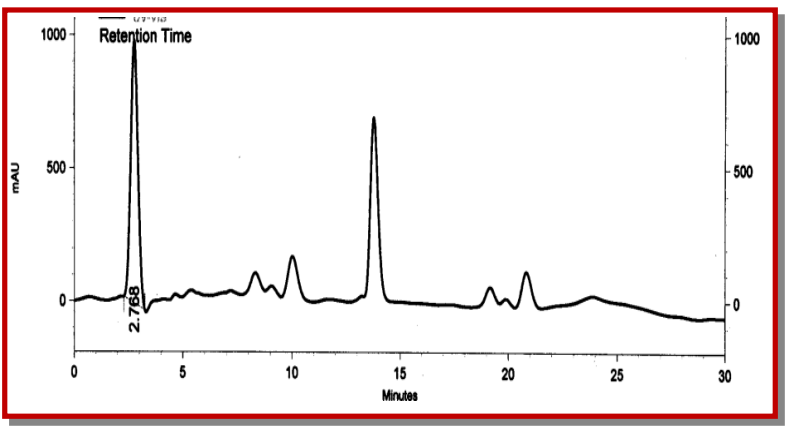

Figure 1: HPLC chromatogram of Sandimmun Neoral â capsule extracted at $215 \mathrm{~nm}$ showing cyclosporin A peak at 2.77

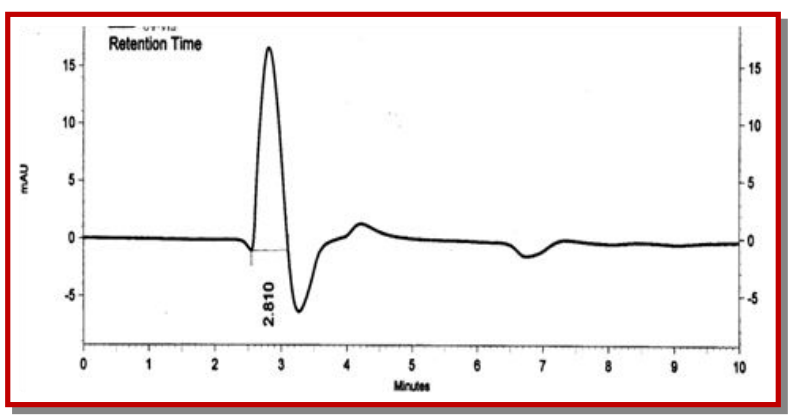

Figure 2: HPLC chromatogram of Sandimmun Neoralâ capsule extracted at $215 \mathrm{~nm}$. Showing cyclosporin 'A' peak at 2.768

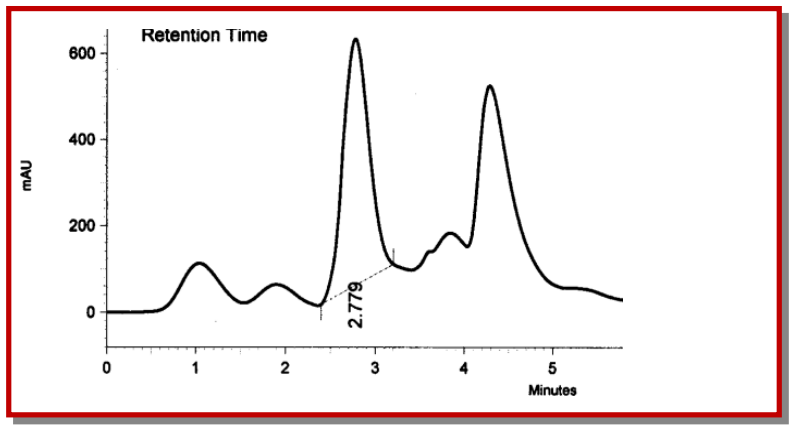

Figure 3: HPLC chromatograms of T. harzianum extracted at $215 \mathrm{~nm}$. Peaks appeared at 2.779 in chromatogram identified as cyclosporin A

(2003) recorded cyclosporin A peak at 3.03 which was produced by Aspergillus terreus following almost similar experimental plan as is described in this study.

Among five tested Trichoderma species only $T$. harzianum (FCBP 140) isolated from air showed a comparable peak at 2.78 (Figure 3). The ESI-MS analysis showed the ion $[\mathrm{CsA}+\mathrm{H}]+$ at $\mathrm{m} / \mathrm{z} 1203$. The estimated yield of cyclosporine A was $44.1 \mu \mathrm{g} / \mathrm{mL}$ with a 0.26 $\mathrm{g} / 50 \mathrm{~mL}$ of fungal biomass. No such peak was recorded in other tested species. However, this quantity was found lower to that recorded by earlier workers in the most studied fungal strain i.e., T. inflatum. As Dreyfuss et al. (1976) and Agathos et al. (1986) found a very good yield of $105.5 \mathrm{mg} / \mathrm{L}$ and Balakrishnan and Pandey (1996) showed that T. inflatum can produce higher levels of cyclosporin A up to $183 \mathrm{mg} / \mathrm{L}$.
Beside T. inflatum so far this drug has been reported to be produced from Aspergillus terreus, Fusarium solani and Fusarium oxysporum (Sallam et al., 2003). This study confirms $T$. harzianum as a new fungal source of cyclosporine A production.

\section{References}

Agathos SN, Marshell JW, Maraiti C, Parekh R, Modhosingh C. Physiological and genetic factors for process development of cyclosporin fermentation. J Industrial Microbiol. 1986; 1: 3948.

Ajith PS, Lakshmidevi N. Effect of volatile and non-volatile compounds from Trichoderma spp. against Colletotrichum capsici incitant of Anthracnose on Bell peppers. Nat Sci. 2010; 8: 265-69.

Borel JF, Feurer C, Magnee AC, Stahelin H. Effects of the new anti-lymphocytic peptide cyclosporin $\mathrm{A}$ in animals. Immunology 1977; 32: 1017-25.

Borel JF. Cyclosporin and its future In: Cyclosporin. Borel JF (ed). Progress in Allergy. Vol. 38. Switzerland, Karger, Basel, 1986, pp 9-18.

Balakrishnan K, Pandey A. Growth and Cyclosporin A production by an indigenously isolated strain of Tolypocladium inflatum. Folia Microbiol. 1996; 41: 401-06.

Deo YM, Gaucher GM. Semi-continuous and continuous production of penicillin $G$ by Penicillium chrysogenum cells immobilized in K-carrageenan beads. Biotechnol Bioeng. 1984; 2: 285-95

Dreyfuss M, Harri E, Hofmann H, Kobel H, Pache W. Tscherter H. Cyclosporin A and C: New metabolites from Trichoderma polysporum. European J Appl Microbiol. 1976; 3: 125-33.

Gams W. Tolypocladium. Eine Hyphomycetengattung mit geschwollenen Phialiden. Persoonia. 1971; 6: 185-91.

IARC. Pharmaceutical Drugs. IARC Monographs on the evaluation of carcinogenic risk of chemicals to humans. International Agency for Research on Cancer, 1990, pp 415.

Park NS, Park HJ, Han K, Kim ES. Heterologous expression of novel cytochrome P450 hydroxylasegenes from Sebekia benihana. J Microbiol Biotechnol. 2006; 16: 295-98.

Sallam LA, El-Refai AM, Hamdi AH, El-Minofi A, AbdElsalam. Studies on the applications of immobilization technique for the production of cyclosporin A by a local strain of Aspergillus terreus. J Gen Appl Microbial. 2005; 51: 143-49.

Sallam LRA, Abdel-Monem H, El-Refai, Abdel-Hamid A, Hassaan A, El-Minofi, Ibrahim S, Abdel-Salam. Role of some fermentation parameters on cyclosporin A production by a new isolate of A. terreus. J Gen Appl Microbial. 2003; 49: 32128

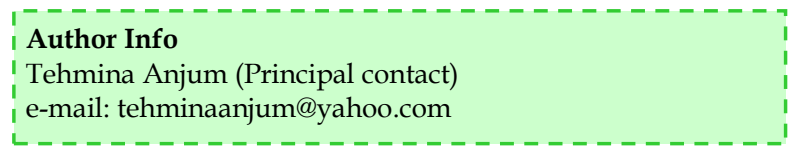

